DOI: http://dx.doi.org/10.18203/2320-1770.ijrcog20191515

\title{
Study of cases with perinatal mortality
}

\author{
Nidhi Pancholi* \\ Department of Obstetrics and Gynecology, BJ Medical College, Ahmedabad, Gujarat, India
}

Received: 17 March 2019

Accepted: 27 March 2019

\section{*Correspondence:}

Dr. Nidhi Pancholi,

E-mail: nidhi_pancholi@ymail.com

Copyright: $\odot$ the author(s), publisher and licensee Medip Academy. This is an open-access article distributed under the terms of the Creative Commons Attribution Non-Commercial License, which permits unrestricted non-commercial use, distribution, and reproduction in any medium, provided the original work is properly cited.

\section{ABSTRACT}

Background: Perinatal loss is one of the most traumatic life events. It is indeed a great psychological and emotional shock to not only the mother and father but the entire family and society as a whole. The perinatal mortality rate (PMR) is an important indicator of the quality of obstetric care during pregnancy. Perinatal deaths result largely from obstetric complications that can be prevented with proper antenatal care and quality neonatal services. The study was aims to study the factors related with perinatal loss and its prevention in future pregnancy.

Methods: It was a prospective analytical study. All patients with IUFD, stillbirths and early neonatal loss were studied. Postpartum both mother and father were counselled. Detailed history and thorough physical examination were conducted. Data was recorded and tabulated, observation made and compared with results of various studies.

Results: The results showed that the incidence of IUFD was 3.7\% and early neonatal death was $10.8 \%$ per total admissions. The perinatal mortality rate was 63.62 per 1000 live births. Perinatal mortality rate was inversely related to the number of antenatal visits taken by the patient. Lack of antenatal care results in perinatal deaths probably due to failure of early identification and management of maternal problems that impact negatively on perinatal outcome. Even in advanced economies with sophisticated diagnostic and monitoring equipment, lack of antenatal care categorizes a pregnant woman as a high-risk pregnancy.

Conclusions: There is a need for awareness regarding importance of antenatal care and institutional delivery. Perinatal mortality is an important indicator of maternal care, health and nutrition. It also reflects the quality of Obstetric and Pediatric care available. Every effort must be made to reduce perinatal mortality.

Keywords: Live birth, Late foetal death, Neonatal period, Perinatal period, Still birth

\section{INTRODUCTION}

God has given us life to see this beautiful world. Perinatal loss is one of the most traumatic life events. It is indeed a great psychological and emotional shock to not only the mother and father but the entire family and society as a whole. Neonatal deaths and still births arise from poor maternal health, inadequate care during pregnancy, inappropriate management during pregnancy and delivery, poor hygiene during delivery and the first critical hours after birth and lack of neonatal care. Perinatal mortality is taken as an index of the efficacy of not only antenatal and intranatal care but also of the socioeconomic condition of the community. ${ }^{1}$

The perinatal mortality rate (PMR) is an important indicator of the quality of obstetric care during pregnancy. $^{2-4}$ Perinatal deaths result largely from obstetric complications that can be prevented with proper antenatal care and quality neonatal services. ${ }^{5}$ In designing interventions/strategies to reduce perinatal mortality, it is important to know its magnitude, causes, and determinants in a given locality. ${ }^{6}$ The World health organization (WHO) estimated that of the 133 million 
live births in 2004 worldwide,3.7 million died in the neonatal period, with 3 million $(76 \%)$ occurring in the early neonatal period. ${ }^{7}$ Ninety-eight percent of the deaths took place in the developing world, where $90 \%$ of babies were born. In addition, for every early neonatal death, an infant was stillborn implying 3 million stillbirths per year. One-third of the stillbirths occurred during delivery from largely preventable causes. ${ }^{4}$ The purpose of this study is to identify the magnitude of perinatal deaths, their immediate causes, to evaluate various factors and determinants related to perinatal mortality, to take care of the patients and also to prevent it in subsequent pregnancies.

\section{METHODS}

This study was a prospective analytical study done in a tertiary care institute. Cases were recruited from the maternity unit of the three hospitals. Cases are defined as deaths of fetuses and infants from the 28th week of gestational life through the $7^{\text {th }}$ day after birth. They fell into two categories.

- Stillbirths: Fetuses that have died prior to their complete expulsion or extraction from the mother. A weight of 1000 grams (corresponding to 28 weeks gestation and crown-heel length of $35 \mathrm{~cm}$ ) was used as the limit of fetal viability in this study. All stillbirths were further classified into fresh and macerated stillbirths.

- Fresh stillbirths were babies born stillbirth without skin disintegration, skull softening, and lack skin and umbilical cord staining from darkened amniotic fluid. These infants are assumed to have died $<12$ hours prior to delivery. Macerated stillbirths on the other hand have disintegrated peeling skin, skull softening, and umbilical cord discoloration by darkened amniotic fluid. Death has usually occurred more than 12 hours prior to delivery. All live births that died in the hospital within 7 days of delivery whether delivered in the same institute or referred from outside.

\section{Inclusion criteria}

- All fresh stillbirths delivered in any of the three hospitals during the study period,

- All macerated stillbirths delivered in any of the three hospitals during the study period,

- All live births delivered in hospital or referred from outside during the study period that died within 7 days of delivery.

\section{Exclusion criteria}

- Denial of consent of the caregiver of an eligible subject,

- Inability to estimate the gestational age of the baby,

- Failure to trace the baby after delivery (outcome unknown).
On admission of the antenatal patients, detailed history was taken, examined thoroughly, investigations done and managed accordingly.

Patients were monitored throughout the labour and complications were managed, if any. The findings were recorded and then tabulated. Observation was made and compared with results of various studies. These patients were followed up for six months postpartum and counselled regarding prevention of perinatal loss in future pregnancy.

\section{RESULTS}

Table 1 shows that the incidence of IUFD was $3.7 \%$ and early neonatal death was $10.8 \%$ per total admission and perinatal mortality rate was 63.62 per 1000 live births.

Table 1: Incidence.

\begin{tabular}{|l|l|}
\hline No. of deliveries & No. of patients \\
\hline No. of IUFD & 3488 \\
\hline$\%$ of IUFD & 131 \\
\hline No. of NICU admissions & 3.7 \\
\hline $\begin{array}{l}\text { No. of babies delivered at institute } \\
\text { No. of babies outside delivered and } \\
\text { admitted at institute }\end{array}$ & 1043 \\
\hline No. of deaths & 696 \\
\hline $\begin{array}{l}\text { \% of early neonatal deaths (per total } \\
\text { NICU admissions) }\end{array}$ & 113 \\
\hline
\end{tabular}

The denominator was taken as the sum of total deliveries in one year plus the number of outside admissions in NICU.

Table 2: Antenatal visits.

\begin{tabular}{|ll|lll|}
\hline No. of antenatal visits & 0 & 1 & 2 & 3 \\
\hline No. of cases & 33 & 14 & 01 & 02 \\
\hline$\%$ of cases & 66 & 28 & 02 & 04 \\
\hline
\end{tabular}

Table 2 shows that perinatal loss was more in patients having no antenatal visits as compared to those who received it. Perinatal loss occurred in $94 \%$ cases with no or only one antenatal visit as compared to $6 \%$ cases with two or three antenatal visits, which stresses the significance of regular antenatal care in pregnancy.

Table 3: Mode of delivery.

\begin{tabular}{|lll|}
\hline Mode of delivery & No. of cases & $\%$ of cases \\
\hline Vaginal delivery & 38 & 76 \\
\hline Caesarean section & 09 & 18 \\
\hline Laparotomy & 03 & 06 \\
\hline
\end{tabular}

Table 3 shows that $76 \%$ of perinatal loss had vaginal delivery, while in $18 \%$ cases caesarean section was needed, laparotomy in $6 \%$ cases. Caesarean section was 
required for indications like obstruction, previous c section, primi breech, meconium stained liquor, laparotomy was done for rupture uterus.

Table 4: Birth weight.

\begin{tabular}{|ll|l|}
\hline Birth weight $(\mathrm{kg})$ & No. of cases & $\%$ of cases \\
\hline $1.0-1.5$ & 05 & 9.8 \\
\hline $1.6-2.0$ & 09 & 17.64 \\
\hline $2.1-2.5$ & 13 & 25.4 \\
\hline $2.6-3.0$ & 20 & 39.2 \\
\hline$\geq 3.1$ & 04 & 7.8 \\
\hline
\end{tabular}

Table 4 shows that $64.6 \%$ of perinatal loss occurred in those with birth weight above $2.0 \mathrm{~kg}$. These were the cases where maximum difficulty was faced during counselling.

Table 5: Cause of perinatal loss.

\begin{tabular}{|lll|}
\hline Cause & No. of cases & \% of cases \\
\hline Idiopathic & 13 & 26 \\
\hline Antepartum haemorrhage & 04 & 08 \\
\hline Oligohydramnios & 04 & 08 \\
\hline Preeclampsia & 07 & 14 \\
\hline Rupture uterus & 03 & 06 \\
\hline Obstruction & 01 & 02 \\
\hline Cord prolapse & 01 & 02 \\
\hline Congenital anomaly & 03 & 06 \\
\hline $\begin{array}{l}\text { Meconium stained liquor/ } \\
\text { meconium aspiration } \\
\text { syndrome }\end{array}$ & 02 & 04 \\
\hline Fever (P. Falciparum) & 01 & 02 \\
\hline Jaundice & 01 & 02 \\
\hline $\begin{array}{l}\text { Intra uterine growth } \\
\text { retardation }\end{array}$ & 01 & 02 \\
\hline Birth asphyxia & 03 & 06 \\
\hline Septicaemia & 03 & 06 \\
\hline $\begin{array}{l}\text { Respiratory distress } \\
\text { syndrome }\end{array}$ & 01 & 02 \\
\hline $\begin{array}{l}\text { Congenital heart disease } \\
\text { Hyaline membrane disease }\end{array}$ & 01 & 02 \\
\hline & 01 & 02 \\
\hline
\end{tabular}

Table 5 shows that the most common cause of perinatal loss was idiopathic (26\%), followed by preeclampsia (14\%), oligohydramnios and antepartum haemorrhage $(8 \%)$.

Table 6 showed that emotional upset occurred in 100\% cases, DIC, retained placenta, bladder injury, puerperal pyrexia, breast engorgement in $4,2,2,2,2 \%$ cases respectively. Necessary steps were taken for complications like blood components were given in DIC, manual removal of placenta done for retained placenta, 2layer closure of bladder injury, higher antibiotics for puerperal pyrexia, cold packs breast bandage for breast engorgement, psychological care for emotional upset.
Table 6: Complications.

\begin{tabular}{|lll|}
\hline Complications & No. of cases & \% of cases \\
\hline DIC & 02 & 04 \\
\hline Retained placenta & 01 & 02 \\
\hline Bladder injury & 01 & 02 \\
\hline Puerperal pyrexia & 01 & 02 \\
\hline Emotional upset & 50 & 100 \\
\hline Breast engorgement & 01 & 02 \\
\hline
\end{tabular}

\section{DISCUSSION}

This study has demonstrated that perinatal mortality remains a significant problem, perinatal mortality rate was 63.62 per 1000 live births which was higher than census India report of PMR 23, 28, 32 per 1000 live birth in the year 2015, 2012, 2010 respectively. ${ }^{8,9,10}$

The PMR in this study may be higher than expected from a community-based study because the study centers attend to referrals from primary and other secondary centers. Most normal deliveries are taken in primary and secondary centers, while the complicated ones are referred. This reduces the denominator and thus exaggerates the PMR. Lack of antenatal care results in perinatal deaths probably due to failure of early identification and management of maternal problems that impact negatively on perinatal outcome. Even in advanced economies with sophisticated diagnostic and monitoring equipment, lack of antenatal care categorizes a pregnant woman as a high-risk pregnancy.

This obviously becomes more so in developing and under developed countries where the availability of basic equipment and consumables is a major challenge. Many studies have demonstrated the role of lack of antenatal care in poor perinatal outcome. ${ }^{6,11}$ It not only detects complications earlier but also helps in education of patients. ${ }^{11}$ The time of starting first ANC and total number of $\mathrm{ANC}$ visits that pregnant women receive and not attending the recommended ANC services may lead to adverse perinatal outcomes. ${ }^{12}$

The study showed that $64.6 \%$ of perinatal loss occurred in those with birth weight above $2.0 \mathrm{~kg}$. These were the cases where maximum difficulty was faced during counselling. According to Daftary $\mathrm{S}$ et al, and Chakravarti SS et al, $40 \%$ of all stillbirth and $80 \%$ of all neonatal deaths were associated with birth weight less than $2.5 \mathrm{~kg} .{ }^{13}$ In present study, low birth weight babies (< $2 \mathrm{~kg}$ ) were admitted to NICU soon after birth where they survived early neonatal period, hence in present study authors found $64.6 \%$ perinatal mortality in birth weight above $2.0 \mathrm{~kg}$. The strong association between birth weight and perinatal mortality is due both to gestational age and to factors unrelated to gestational age. ${ }^{14}$ This study showed that the most common cause of perinatal loss was idiopathic (26\%), followed by Preeclampsia (14\%), oligohydramnios and antepartum hemorrhage 
(8\%). According to WHO estimates, in developing countries, asphyxia causes around seven deaths per 1000 live births, whereas in developed countries this proportion is less than one. ${ }^{15}$ According to a study obstetrical complication associated with perinatal mortality were antepartum hemorrhage (4.35\%), eclampsia (10.32\%), obstructed labour $(8.15 \%)$, and malpresentation $(11.96 \%)$.

Unexplained or idiopathic contributed to $13.58 \% .^{1}$ This study signifies that majority of the cause of perinatal mortality was related to obstetrics. Hence, to reduce perinatal mortality rate authors need to improve antenatal care of patients. Early identification of risk factors and appropriate intervention is important to bring down perinatal mortality. ${ }^{1}$

Perinatal mortality is an important indicator of maternal care, health and nutrition. It also reflects the quality of Obstetric and Paediatric care available. Every effort must be made to reduce perinatal mortality. In many societies, neonatal deaths and stillbirths are not perceived as a problem, largely because they are very common.

Many communities have adapted to this situation by not recognizing the birth as complete, and by not naming the child, until the newborn infant has survived the initial period. Health workers at primary and secondary level of care often lack the skills to meet the needs of newborn infants, since recognition of opportunity is only emerging in countries, and their experience in this area is therefore limited. ${ }^{15}$

Every effort must be made to instill the importance of antenatal care in the society. The more antenatal visit a woman would take higher the chances of detecting high risk factor, so that it can be managed at the earliest.

\section{CONCLUSION}

The perinatal mortality rate (PMR) is an important indicator of the quality of obstetric care during pregnancy. Perinatal deaths result largely from obstetric complications that can be prevented with proper antenatal care and quality neonatal services.

Proper and early management of complications must be done in the intra partum period. There is a need for awareness regarding importance of antenatal care and institutional delivery. Perinatal mortality is an important indicator of maternal care, health and nutrition. It also reflects the quality of Obstetric and Paediatric care available. Every effort must be made to reduce perinatal mortality.

\section{ACKNOWLEDGMENTS}

Authors would like to thank patients who agreed to participate in this study and the staff who helped recruit patients.
Funding: No funding sources

Conflict of interest: None declared

Ethical approval: Not required

\section{REFERENCES}

1. Srivastava S, Sharma S, Kharkwal S, Chaudhary V. A study of causes of perinatal mortality in tertiary centre in Bundelkhand region. Int $\mathrm{J}$ Reprod Contracept Obstet Gynecol. 2015;4:43-6.

2. Richardus JH, Graafmans WC, Verloove-Vanhorick SP, Mackenbach JP. The perinatal mortality rate as an indicator of quality of care in international comparisons. Medical Care. 1998:54-66.

3. Richardus JH, Graafmans WC, Verloove-Vanhorick SP, Mackenbach JP. Differences in perinatal mortality and suboptimal care between 10 European regions: results of an international audit. BJOG: Int J Obstet Gynaecol. 2003;110(2):97-105.

4. Sugai MK, Gilmour S, Ota E, Shibuya K. Trends in perinatal mortality and its risk factors in Japan: Analysis of vital registration data, 1979-2010. Scientific Reports. 2017;7:46681.

5. Neonatal and Perinatal Mortality: Country, Regional and Global Estimates 2000. Geneva: World Health Organization (2006). Accessed at: https://apps.who.int/iris/handle/10665/43444.

6. Suleiman MB, Mokuolu OA. Perinatal mortality in a Northwestern Nigerian City: a wakeup call. Frontiers Pediatr. 2014;2:105.

7. Åhman E, Zupan J, eds. Neonatal and perinatal mortality: country, regional and global estimates 2004. Geneva: World Health Organization (2007). Available at: http://www.who.int/iris/handle/10665/438001.

8. Estimates of mortality indicators-census of India. Available http://www.censusindia.gov.in/vital statistics/SRS Report_2015/8.Chap\%204-Mortality\%20Indicators2015.pdf. Accessed on 16 May 2018.

9. Figures at a glance, India-2012-census of India. Available at: http://www.censusindia.gov.in/2011common/vital\%20Rates.pdf. Accessed on 16 May 2018.

10. Estimates of mortality indicators -census of India. Available :http://www.censusindia.gov.in/vital_statistics/srs/Ch ap_4-2010.pdf. Accessed on 16 May 2018.

11. Ante D. Antenatal Care in developing countries. What should be done?. J Per Med. 2001;29(3):18898.

12. Haftu A, Hagos H, Mehari MA. Pregnant women adherence level to antenatal care visit and its effect on perinatal outcome among mothers in Tigray Public Health institutions, 2017: cohort study. BMC Res Notes. 2018;11(1):872.

13. Daftary S, Sudip Chakravarti S, ed. Manual of Obstetrics, $3^{\text {rd }}$ ed. Reed Elsevier India Pvt. Limited. 2011. 
14. Wilcox AJ, Skjaerven R. Birth weight and perinatal mortality: the effect of gestational age. Am J Public Health. 1992;82(3):378-82.

15. Neonatal and perinatal mortality-World health Organisation. Available at: https://apps.who.int/iris/bitstream/handle/10665/434 44/9241563206_eng.pdf?sequence=1. Accessed on 16 May 2018.
Cite this article as: Pancholi N. Study of cases with perinatal mortality. Int J Reprod Contracept Obstet Gynecol 2019;8:1719-23. 